Mazzola, E., Acur, N. , Piazza, M. and Perrone, G. (2018) 'To own or not to own?' A study on the determinants and consequences of alternative intellectual property rights arrangements in crowdsourcing for innovation contests. Journal of Product Innovation Management, 25(6), pp. 908-929.

There may be differences between this version and the published version. You are advised to consult the publisher's version if you wish to cite from it.

This is the peer reviewed version of the following article:

Mazzola, E., Acur, N. , Piazza, M. and Perrone, G. (2018) 'To own or not to own?' A study on the determinants and consequences of alternative intellectual property rights arrangements in crowdsourcing for innovation contests. Journal of Product Innovation Management, 25(6), pp. 908-929. (doi: 10.1111/jpim.12467)

This article may be used for non-commercial purposes in accordance with Wiley Terms and Conditions for Self-Archiving.

http://eprints.gla.ac.uk/168116/

Deposited on: 04 September 2018

Enlighten - Research publications by members of the University of Glasgow http://eprints.gla.ac.uk/ 


\title{
'TO OWN OR NOT TO OWN?' A STUDY ON THE DETERMINANTS AND CONSEQUENCES OF ALTERNATIVE INTELLECTUAL PROPERTY RIGHTS ARRANGEMENTS IN CROWDSOURCING FOR INNOVATION CONTESTS
}

\author{
Erica Mazzola \\ Department for Industrial and Digital Innovation - University of Palermo \\ Nuran Acur* \\ Adam Smith Business School - University of Glasgow
}

\section{Mariangela Piazza}

Department for Industrial and Digital Innovation - University of Palermo

\section{Giovanni Perrone}

Department for Industrial and Digital Innovation - University of Palermo

\footnotetext{
*Address correspondence to: Prof. Nuran Acur, Adam Smith Business School, Gilbert Scott Building, University Avenue - Glasgow G12 8QQ. E-mail: nuran.acur@glasgow.ac.uk
} 


\section{BIOGRAPHICAL SKETCHES}

Dr. Erica Mazzola is Assistant Professor of Management Engineering at the Department for Industrial and Digital Innovation (DIID) of the University of Palermo. Her main research interests are: open innovation, crowdsourcing and corporate venture capital. In addition, her interests include research on strategic alliances and inter-firm networking strategies. In these areas, she published for several leading international journals of innovation and operation management, among others - Journal of Product Innovation Management, British Journal of Management and International Journal of Production Economics.

Nuran Acur is Professor of Innovation Management and program director of the Master of Global Business programme at Adam Smith Business School, University of Glasgow, United Kingdom. She received her Ph.D. in strategic management from the University of Strathclyde. Previously, she worked at Strathlyde University (UK), Ozyegin University (Turkey), Aalborg University (Denmark) and Bilkent University (Turkey). She is an editorial board member of Journal of Product Innovation Management and Creativity and Innovation Management. Nuran has published award winning, theorydriven, policy - and practice - relevant articles across the fields of technology innovation, open innovation, digital innovation and innovation strategy. Maintaining a consistently upward trajectory of funded research projects, she has secured more than $£ 690 \mathrm{k}$ of research funding from: The Engineering and Physical Sciences Research Council (EPSRC), ESRC, Innovate UK, The Scientific and Technological Research Council of Turkey (TÜBİTAK) and Scottish Enterprise- Open Innovation Project. Her work has appeared in the Journal of Product Innovation Management, European Management Review, International Journal of Operations \& Production Management, Creativity and Innovation Management, Supply Chain Management: an International Journal, and other scholarly journals.

Mariangela Piazza is a PhD student in Technological Innovation Engineering at the Department for Industrial and Digital Innovation (DIID) of the University of Palermo. Her main research interest is focused on the study of open innovation paradigm. Particularly, she is investigating a wide range of issues related to the crowdsourcing phenomenon and to the corporate venture capital investments.

Giovanni Perrone is full Professor of Management Engineering at the Department for Industrial and Digital Innovation (DIID) of the University of Palermo. His research is mainly focused on open innovation, inter-firm relationships and entrepreneurship. His research has been published in leading innovation and operation management journals including, among others - Research Policy, British Journal of Management, International Journal of Production Economics. Prof. Perrone currently is Department Head, President of the European Operations Management Association (EurOMA) and President of the Italian National Association of University Business Incubators (PNICube). 


\begin{abstract}
Firms are increasingly engaging in crowdsourcing for innovation to access new knowledge beyond their boundaries; however, scholars are no closer to understanding what guides seeker firms in deciding the level at which to acquire rights from solvers and the effect that this decision has on the performance of crowdsourcing contests. Integrating Property Rights Theory and the problem solving perspective whist leveraging exploratory interviews and observations, we build a theoretical framework to examine how specific attributes of the technical problem broadcast affect the seekers' choice between alternative intellectual property rights (IPR) arrangements that call for acquiring or licensing-in IPR from external solvers (i.e. with high and low degrees of ownership respectively). Each technical problem differs in the knowledge required to be solved as well as in the stage of development it occurs of the innovation process and seeker firms pay great attention to such characteristics when deciding about the IPR arrangement they choose for their contests. In addition, we analyze how this choice between acquiring and licensing-in IPR, in turn, influences the performance of the contest. We empirically test our hypotheses analyzing a unique dataset of 729 challenges broadcast on the InnoCentive platform from 2010 to 2016. Our results indicate that challenges related to technical problems in later stages of the innovation process are positively related to the seekers' preference toward IPR arrangements with a high level of ownership, while technical problems involving a higher number of knowledge domains are not. Moreover, we found that IPR arrangements with a high level of ownership negatively affect solvers' participation and that IPR arrangement plays a mediating role between the attributes of the technical problem and the solvers' self-selection process. Our article contributes to the open innovation and crowdsourcing literature and provides practical implications for both managers and contest organizers.
\end{abstract}

Keywords: Crowdsourcing for innovation; Intellectual Property Rights; Challenge performance; Property Rights Theory; InnoCentive platform.

\title{
PRACTITIONER POINTS
}

- Seeker firms have to align their decisions about acquiring or licensing the IPR to the winning solution with the attributes of the technical problem they are attempting to solve (i.e. the stage of development and the nature of knowledge).

- Since it is possible to capture a higher value from reduction to practice (RTP) challenges than from an ideation or a theoretical challenge, seeker managers should acquire the IPR to the winning solution when broadcasting RTP challenges.

- Seeker firms should choose to license-in the IPR to the solution of a technical problem involving a greater number of different knowledge domains.

- Firms have to consider the effects that the IPR arrangement has on the performance of the contest. Managers have to be aware that by choosing to acquire the IPR to the winning solution, solvers may be discouraged from participating in that contest. 


\section{INTRODUCTION}

Crowdsourcing for innovation contests are one of the most powerful Open Innovation (OI) activities that firms are increasingly engaging in to access new knowledge originating from outside their boundaries (Chesbrough, 2003; Majchrzak and Malhotra, 2013). An innovation contest is a knowledge-intensive process wherein external solution providers, i.e. solvers, self-select and generate intellectual assets such as ideas, technologies, commercialization plans, business processes and business model designs, in order to solve technical problems broadcast by firms, i.e. seekers (Afuah and Tucci, 2012; Mount and Martinez, 2014). The intellectual assets produced by solvers can be used as value capture mechanisms by seekers (James, Leiblein and Lu, 2013; Pisano and Teece, 2007). Such assets, in fact, are mostly protected as intellectual property (IP), thereby granting to the asset's owner a bundle of IP rights (IPR) that include ownership and usage rights to exploit the intellectual properties (Ayerbe et al., 2014; Brem, Nylund and Hitchen, 2017; Chen, Bharadwaj and Goh, 2017).

Despite the fact that research concerning IPR arrangements is gaining a noteworthy role in the innovation context for idea generation (e.g. Bauer, Franke and Tuertscher, 2016; de Beer et al., 2017; Tietze, Pieper and Herstatt, 2015), scholars are no closer to understanding what guides seeker firms in deciding the level at which to acquire rights from solvers and the effect that this decision has on the performance of crowdsourcing contests. Previous crowdsourcing research has addressed the protection issues of IPR, highlighting how seekers and solvers are concerned about protecting their intellectual property when broadcasting technical problems and submitting solution proposals respectively (Bauer, Franke and Tuertscher, 2016; Feller et al., 2012; Garavelli et al., 2013). Whilst some scholars have focused on the role played by crowdsourcing platforms in protecting both seekers and solvers' IPR (Feller et al., 2012; Garavelli et al., 2013), others have studied the rules that regulate the use of IPR among solvers (Bauer, Franke and Tuertscher, 2016). What has been neglected by crowdsourcing scholars are the ownership issues of IPR that concern who, between the seeker and solver, owns and controls the IPR 
associated with the winning solution. To the best of our knowledge, the only exception is a recent study by de Beer et al. (2017) that focused on the legal problems a seeker faces when acquiring IPR from the crowd. Thus, the seeker's decision about the IPR arrangement, i.e. the arrangement that regulates the acquisition of rights from winning solvers, is an issue that remains unexplored in the crowdsourcing literature.

Choosing the IPR arrangement is a non-trivial decision for seekers. Seeker firms need to use IPR arrangements with a high degree of ownership to obtain the right to capture value from the innovation generated in the contests (James, Leiblein and Lu, 2013; Pisano and Teece, 2007; Zobel, Lokshin and Hagedoorn, 2017), since a necessary condition for a solution proposal to become a source of competitive advantage is that it is not usable by others companies such as competitors (Shenk et al., 2017). However, using tighter IPR arrangements could jeopardize the creation of value during the innovation contest since solvers are often afraid to share or cede their ownership and usage rights (de Beer et al., 2017; Ye and Kankanhally, 2017). Thus, seekers must be mindful when taking a decision about the ownership level of the IPR arrangement in crowdsourcing activities. Specifically, it could be helpful for contest organizers to find guidance about how to design IPR arrangements which balance the solvers' concerns about sharing or ceding their IPR and the seekers' need to capture sufficient rights to achieve organizational objectives.

This article aims to examine the antecedents that guide seekers in choosing a level of ownership of IPR arrangements (acquiring or licensing-in) when designing technical innovation contests to acquire intellectual property from the winning solvers. In addition, it analyzes how this choice between acquiring and licensing-in intellectual property, in turn, influences the performance of the contest. Thus, considering both the antecedents and the consequences of IPR arrangement choices, this article explores the mediating role of IPR in the crowdsourcing context. 
Following the distinction made by de Beer et al. (2017), the degree of ownership of IPR arrangements can range between a high degree of ownership, in which the seeker fully acquires the IPR related to the winning solution from the solver and a low degree of ownership, in which the seeker licenses-in it. The seeker may decide between these alternative degrees of ownership by considering the value she/he can capture from the knowledge and technologies developed by solvers. In exploring what influences seekers in taking these decisions, we evoke the problem solving perspective (Nickerson and Zenger, 2004; Nickerson, Wuebker and Zenger, 2017). Moreover, since solvers may be afraid to share or cede their ownership and usage rights (de Beer et al., 2017; Ye and Kankanhally, 2017), we argue that the choice of IPR arrangements between those with different degrees of ownership differently influences the performance of the contest by affecting the self-selection of solvers. Finally, we hypothesize that the IPR arrangement in the crowdsourcing context plays a mediating role between the attributes of the problem broadcast and the performance of the crowdsourcing contest.

The design of this research has followed a two-step approach highlighted in research by Belderbos et al (2014). In the first step, we participated an Open Innovation (OI) programme run by Scottish Enterprise and explored the crowdsourcing for innovation projects of multinational companies in order to develop a deeper understanding of the crowdsourcing for innovation phenomenon and IPR issues from the seekers' perspective. The one of the author observed three organizations' OI programme for a year in 2016 and conducted interviews with open innovation managers. Interviews were used to complement the theoretically grounded arguments for IPR arrangements in crowdsourcing for innovation contests and develop the hypotheses shaping the theoretical framework. At this stage in the first step of our approach, drawing on Property Rights Theory (PRT) and the problem solving perspective literature (Alchian and Demsetz, 1972; Grossman and Hart, 1986; Hart and Moore, 1990; Nickerson and Zenger, 2004), and considering our observations and interview findings, hypotheses about the antecedents of the IPR arrangement decision were developed. Moreover, using insights from the 
interviewed companies, together with previous crowdsourcing literature addressing solvers' motivation (e.g. Ye and Kankanhally, 2017; Zhao and Zhu, 2014), hypotheses about the consequences of IPR arrangement decisions were stated. In the second step of our research the theoretical framework was empirically validated, building a cross-sectional dataset from 729 challenges awarded in a seven-year time window (from 2010 to 2016) on the InnoCentive crowdsourcing platform.

The present research offers several contributions to the OI and crowdsourcing literatures. First, this study broadens the understanding of ownership issues in the crowdsourcing context by highlighting the role played by the IPR arrangement. This work extends research on the legal aspects of crowdsourcing contests by addressing the antecedents a seeker firm focuses on when deciding the degree of ownership to use in order access intellectual assets from the crowd. Second, this research contributes to the literature that focuses on crowdsourcing performance by demonstrating how alternative IPR arrangements have leverage on the solvers' self-selection process. Third, the article adds to the OI debate about the role of appropriation mechanisms by highlighting the relevant role played by IPR arrangements for seekers aiming to capture value from crowdsourcing contests. Finally, this study provides managers and contest organizers with specific guidance on how to choose IPR arrangements when designing crowdsourcing for innovation contests and advise them about the effect of different IPR arrangements on the participation of solvers.

\section{THEORETICAL AND EMPIRICAL BACKGROUND}

\section{Crowdsourcing for innovation, Property Rights Theory and problem-solving perspective}

Property Rights Theory (PRT) has great potential in explaining and envisaging various ownership issues and value capturing phenomena in the crowdsourcing for innovation context (Kim and Mahoney, 2005). According to de Beer et al. (2017: 210) '[...] acquiring is a critical legal aspect of crowdsourcing intellectual property' and they defined it '[...] as the degree (low to high) to which an organization seeks 
to acquire the intellectual property rights of crowd solutions'. Seeker firms decide the degree of ownership they desire to acquire from the winning solver when designing the crowdsourcing contest; they have to declare it before the beginning of the challenge in the problem statements, also called a Request for Proposal (RFP) (de Beer et al., 2017; Lüttgens et al., 2014). Beyond the rules underlying the degree of ownership of the bundle of rights related to the winning solution, that is the IPR arrangement, the RFP describes the attributes of the technical problem, includes any performance criteria the winning solution must meet and sets the prize award the winning solvers will receive in exchange for sharing or ceding their IPR (Lopez-Vega, Tell and Vanhaverbeke, 2016; Lüttgens et al., 2014).

Under the lens of PRT, then, the IPR arrangement defines the party that has the residual control right to the winning solution, that is the ownership and control of the IPR associated with the winning solution (de Beer et al., 2017; Grossman and Hart, 1986; Hart and Moore; 1990). Particularly in the crowdsourcing context 'common types of IPR include patents, trademarks, copyrights, design rights, and technical or commercial information (trade secrets)' (Hagedoorn and Zobel, 2015: 2). As such, owning the residual control right to the winning solution grants several benefits to the owner, such as excluding non-owners from accessing that solution, appropriating economic rents from the use of the solution, and selling or otherwise licensing rights to others (Kim and Mahoney, 2002). Moreover, such ownership advantages, which are monopolistic in nature, can be used to influence the market and hinder competition (Kim and Mahoney, 2002). Thus, determining the party that should benefit from retaining the ownership of the winning solution is a central concern in the crowdsourcing context (Kim and Mahoney, 2005).

Both the seeker and the solver could benefit from owning the residual control rights to the winning solution. If the seeker owns the control rights, she/he could deny the use of the solution to potentially interested competitors and so achieve a monopolistic position for that innovation. If the solver owns the residual control rights, however, she/he could license-out the IPR related to the solution to 
other interested parties or use it to participate in another crowdsourcing contest, thereby gaining additional earnings beyond the seeker's prize award. However, it is the seeker that, in designing the crowdsourcing contest, decides which party, either the seeker or the solver, will own the residual control rights and will obtain the benefits related to the ownership of the winning solution. If the seeker chooses an IPR arrangement with a high degree of ownership, she/he fully acquires the IPR related to the winning solution, thereby gaining the residual control rights to it (Alchian and Demsetz, 1972; de Beer et al., 2017; Grossman and Hart, 1986; Hart and Moore, 1990). In this scenario, the seeker possesses the exclusive right to use the wining solution, while the solver can no longer use or authorize others to use it (de Beer et al., 2017). In contrast, through IPR arrangements with a low degree of ownership seekers obtain a license to use the winning solution (de Beer et al., 2017). In this circumstance, the seeker does not gain the residual control rights related to the winning solution, which are retained by the solver who can continue using that solution and license it out to other parties (Alchian and Demsetz, 1972; de Beer et al., 2017; Grossman and Hart, 1986; Hart and Moore, 1990).

When deciding among different levels of ownership the seekers rely on the attributes of the problem that they would like to solve. The seeker cannot simply choose new knowledge to acquire from the crowd because the desired knowledge is frequently hard to communicate or has not been developed yet (Nickerson and Zenger, 2004). Instead, seekers must define valuable problems that, through their attributes, formalize the knowledge required. Such problem attributes, as for example the stage of development, are the means through which a seeker can solicit knowledge from the crowd. Then, the problem-solving perspective (Nickerson and Zenger, 2004; Nickerson, Wuebker and Zenger, 2017) is used to provide arguments on how seekers catalyze the value-capturing from crowdsourcing by considering the attributes of the problems broadcast and matching these attributes with the modes of acquiring IPR from the crowd. 


\section{Crowdsourcing for innovation and IPR arrangements: evidence from observations and interviews}

To deepen the understanding about issues related to the decision between alternative IPR arrangements, the behavior of three multinational companies (hereafter FirmA, FirmB and FirmC) that leverage on crowdsourcing for innovation to develop new technical products and broadcast contests in crowdsourcing platforms such as InnoCentive and NineSigma was explored. These three organizations are part of the Open Innovation (OI) programme in Scotland (2015-2016) ${ }^{1}$ to which one of the author participated to observe the behavior of organizations in the programme and exchange academic knowledge about OI and crowdsourcing. As part of the programme, there were three cohort meetings where each organization shared its experiences and challenges during OI activities. During these meetings, one of the author recorded notes that helped us learn more about crowdsourcing activities in organizations. The three organizations were also interviewed in December 2016 and the interviews, each lasting between one and two hours, have been recorded and transcribed verbatim. The interview protocol contained questions regarding the IPR arrangements, the companies' OI strategy, and a series of possible drivers and consequences of IPR arrangements.

The interview data was initially analyzed using open coding and subsequently using selective coding based on key concepts from the area of the study. The analysis involved two steps that allow to examine all data collected from multiple perspectives to explore interesting features. First, the one of the author constructed case narratives, including verbatim quotes from interviewees, to provide a rich description of the crowdsourcing for open innovation contest in relation to IPR arrangements. In an approach similar to Jarzabkowski and Balogun (2009), this narrative was then read, discussed and refined by the other researchers acting as 'outsiders' in questioning the narrative themes. Coding of problem attributes and IPR arrangements followed acknowledged classifications from the literature. Second, we defined a description of the open innovation project's activities. Then, we code each case with respect to the problem characteristics, origin, and effects on IPR decision. From the each case 
history, we advanced narratives based on broad categories, and maintain the analysis by using NVivo 8 software till we defined patterns into the seven categories ( see details about categories in corresponding to the interviews in Appendix A). From a critical analysis of these concepts, the following considerations can be retrieved.

First, it was evident that all organizations place value on adopting online crowdsourcing platforms in the acquisition of outside knowledge and intellectual property. They, in fact, consider the IPR issue as one of the most important issue when engaging in crowdsourcing for innovation activities. Moreover, all interviewed organizations indicate the importance of considering the alternative ownership levels of IPR arrangements (high vs. low level of ownership) before publishing the challenge in order to be transparent about the rules underlying the ownership of the winning solution. As the FirmB manager stated, 'The IP concerns are discussed right at the start' and this was also stressed by the FirmA's manager who stated 'I think the reason we put it in is because we want to show that we're not just looking to acquire IP. We're looking to actually work with the people who have invented the idea to help them make their idea better. I think it's important to make sure that's quite clear when you're writing it and putting forward that agreement type'.

Second, based on our observations and interviews, it was found that IPR decisions are typically based on the characteristics of the problem. Each technical problem differs in the knowledge required to be solved as well as in the stage of development it occurs of the innovation process and companies pay great attention to such characteristics when deciding about the IPR arrangement they choose for their contests. For example, the FirmA manager suggested IPR arrangements become more important if they ask solvers to develop technical requirements instead of just generating ideas from by stating that 'The IPR arrangements [are] mainly based on the solver but it's what the technology is, what [the] level of development it is, whether it's early stage or whether we've already exploited it in another industry or anywhere in between and what their capability is and, I guess what comes into it as well, was how they 
are comfortable working. They might have the capability to manufacture lots of products for us but they might actually prefer just to pass over the IP and let us do our own work'.

Finally, all the organizations are aware about the importance that IPR arrangements have for solvers participating to their contests and they really care about the effect that alternatives degree of ownership may have on solvers' participation. The following quotation from FirmB manager nicely captures this point suggesting that 'I think in my experience within my firm we have to be very careful about it because we've had a number of people try to stop our open innovation programme because of their concerns about IP and disclosure to the market'.

\section{HYPOTHESES DEVELOPMENT}

Figure 1 shows the theoretical framework and the relationships hypothesized.

[Figure 1, about here]

\section{Antecedents of IPR arrangements}

Adopting a problem-solving perspective, we argue that the attributes of the technical problem act as antecedents guiding seekers in choosing the most appropriate IPR arrangements to source intellectual assets from the crowd (Nickerson, Wuebker and Zenger, 2017). We particularly posit that two attributes of the technical problem may influence the seekers' choice whether to acquire or license-in the IPR related to the winning solution: the knowledge domains of the technical problem and the stage of development of the technical problem at the moment it is broadcast.

With regard to the first attribute, in a crowdsourcing for innovation challenge seekers can broadcast technical problems that vary in the knowledge required to find a possible solution (Afuah and Tucci, 2012). In particular, the technical problems to be solved can involve a different number of knowledge domains (Boudreau, Lacetera and Lakhani, 2011; Mayer, Somaya and Williamson, 2012). Problems involving a high number of knowledge domains are more complex since their solutions require 
the interaction of different competencies (Kavadias and Sommer, 2009). Thus, when developing a solution proposal that draws on several knowledge domains, solvers have to adopt a solution search process along a frontier of different paths or trajectories (Boudreau, Lacetera and Lakhani, 2011). For example, a complex technical problem related to the development of a novel methodology to recycle cotton materials requires potential solvers to find solutions recombining knowledge from the chemistry, engineering, agriculture, life sciences and physical sciences domains (InnoCentive 2013 - ID challenge: 9933196). Conversely, problems involving low number of technical domains are less complex since they require a low degree of interaction among knowledge domains (Kavadias and Sommer, 2009). In such cases, even if technical problems involving few knowledge domains remain nontrivial, any solver that wants to develop an effective solution proposal can adopt a solving approach which 'can often be somewhat standardized, and even possibly "routinized," at least to some extent' (Boudreau, Lacetera and Lakhani, 2011: 11). Consider, for example, a technical problem related to the development of a new drug molecule; it requires potential solvers to find solutions that draw only on routine synthesis processes related to the chemistry knowledge domain (InnoCentive 2014 - ID challenge: 9933600).

The potential benefits that a seeker can obtain from retaining the IPR to the winning solution could depend on the number of knowledge domains related to the technical problem. Resolution processes that explore multiple paths across different domains, in fact, increase the likelihood of obtaining novel and innovative outcomes compared to proposals that solve problems straddling few knowledge domains (Boudreau, Lacetera and Lakhani, 2011). Thus, the value captured by the seeker from a solution related to technical problems that draw on a higher number of knowledge domains might be higher than that captured by the seeker from solutions related to a lower number of knowledge domains. Thus, when the challenge involves a technical problem characterized by several knowledge domains, the seeker will have a greater interest in owning the residual control to the related bundle of rights (Grossman and Hart, 1986; Hart and Moore; 1990). In fact, in acquiring the full ownership of the 
IPR to such a higher-value winning solution, the seeker could achieve a monopolistic position by hindering the use of that solution to competitors (Kim and Mahoney, 2002; 2005). This argument is reflected in the interview with the manager of FirmB who stated that 'there may be opportunities to look at exclusive use with the right people to say we want to use our product in the oil and gas industry but we don 't' mind if you use that in the medical industry or other industries; that's fine'.

In light of previous discussions, the first hypothesis is stated:

Hypothesis 1: Technical problems involving a higher number of knowledge domains are positively related with IPR arrangements with a high degree of ownership.

The second attribute that may affect seekers in designing the IPR arrangement is the development stage of the technical problem at the moment it is broadcast. Seekers can broadcast challenges related to technical problems at different stages of an innovation development process (Jeppesen and Lakhani, 2010; Zogaj, Ulrich and Leimeister. 2014). Specifically, ideation and theory development challenges concern technical problems related to the early stage of an innovation development process, in which seekers solicit solvers to find novel possible approaches to solve a problem and ask them to theoretically ground those approaches. The reduction-to-practice (RTP) challenges, in turn, concern problems related to the later stage of development, in which seekers solicit solvers to provide prototypes and empirical evidence of ideas and theory (Zogaj, Ulrich and Leimeister. 2014). For example, 'An enzyme stabilizer at high pH is required' is a possible problem statement of RTP challenges, whereas 'Can you formulate a simple, stable, and safe injectable suspension placebo that has no pharmacological and biological activity' is a possible request of theoretical challenges (Jeppesen and Lakhani, 2010: 1020). As such, differently from ideation and theoretical challenges, RTP challenges require solvers to perform complex tasks in order to present physical evidence that proves their solution proposals work according to the seekers' specific needs, decision criteria and manufacturing parameters. The potential benefits seekers 
can obtain from retaining the IPR to the winning solution depend on the stage of the innovation development process of the technical problem broadcast (Chen and Chang, 2010; Kermani and Bonacossa, 2003). This argument is reflected in FirmB interviews, 'If we take an early stage technology and we ask someone to take something that's for use on land and marinise it for use on the sea bed then we need to look at who's going to own the rights to that and will we have an exclusive and free license for that for a period of time.'

Because the development process of an innovation is a risky and expensive process characterized by several technological hurdles and successive investments, the later the stage of development, the higher the likelihood that the developed innovation will succeed (Kermani and Bonacossa, 2003). Consider, for example, the development of a new drug in the later stage of product development; the molecule has already overcome the riskiest step of development, i.e. the phases related to the pre-clinical and clinical trial, which could compromise the drug's approval. Thus, the risk that the new drug development process fails, and the new drug cannot reach the market, is lowest at the later stages of the process. Moreover, in the development process of a new drug, the effort and money spent by the company increases tremendously as the process continues. Therefore, the value captured by seekers from solutions related to RTP challenges might be higher than that captured from solutions related to theory development and ideation challenges. In light of this, when the challenge is related to later stages of the innovation development process, the seeker will have a greater interest in appropriating the residual control to such a bundle of rights (Grossman and Hart, 1986; Hart and Moore; 1990), for example, to achieve a monopolistic position from that innovation (Kim and Mahoney, 2002; 2005). This argument is reflected in FirmB's interview, 'you could have something that's around research or technology development at a last mature stage where people will say "let's invest some money in that and help these companies to bring to market but we will support them to do that'. And we may say if it's a really great idea and it's a really great solution then we want to have exclusive - not necessarily exclusive - use but 
we want to help you and then we want to help ourselves - not help ourselves - but have some kind of relationship that is beneficial to both parties'. Based on above argumentations the second hypothesis of this study arises:

Hypothesis 2: Technical problems related to later-stage development are positively related with IPR arrangements with a high degree of ownership.

\section{Consequences of IPR arrangements}

Existing crowdsourcing literature has highlighted how the wideness of the number of solvers participating in a contest increases the overall performance of the contest (Boudreau, Lacetera and Lakhani, 2011; Jeppesen and Lakhani, 2010; Terwiesch and Xu, 2008). In fact, a large pool of solvers submits a large number of solution proposals, thereby increasing the likelihood of finding at least one good solution (Terwiesch and $\mathrm{Xu}, 2008)$. Seekers, then, are aware of the effect that IPR arrangements with different degrees of ownership have on the performance of their contests (de Beer et al., 2017; Terwiesch and $\mathrm{Xu}, 2008)$. A manager in FirmC supported this argument by saying that 'There has been a previous desire in the company to only use exclusive use relationships and the challenges that we are advertising, these are things that are very difficult to solve so we have to be open-minded about what kind of relationships we want to form with the solvers because we could say we're only going to have exclusive use and then we exclude lots of companies from solving'.

We argue that IPR arrangements have an effect on the performance of contests for two main reasons. First, IPR arrangements may touch solvers' extrinsic motivations for participating in a challenge, i.e. motivations related to the financial earnings derived from performing a challenge (Ye and Kankanhally, 2017). If the seeker decides to acquire the IPR to the winning solution, she/he denies to that solver the possibility of gaining additional financial earnings, for example, by using that solution to submit a proposal in a different crowdsourcing contest (Afuah and Tucci, 2012). Moreover, if the seeker 
decides to fully acquire the IPR of the winning solution, the solver could feel that the amount of effort she/he is putting into solving the challenge is being underestimated (de Beer et al., 2017). In fact, solvers may believe that by taking advantage of fully acquiring the IPR to the winning solution, the seeker could gain greater future earnings related to the ownership of that solution than the prize awarded to the winning solver (Ye and Kankanhally, 2017). Thus, an IPR arrangement with a high degree of ownership, by limiting solvers' future business opportunities, reduces the probability of the solver's self-selection (Ye and Kankanhally, 2017). This is reflected in FirmA's interview, 'I think it would be difficult for the solvers to know whether it's going to be a strong IPR agreement or weak [one] just from reading the challenge but I think probably a lot of people don't even use crowd sourcing to put forward solutions because they are concerned about what happens with their IP at the end of it. So, I guess it does really affect participation, the IPR overall'.

Second, IPR arrangements also touch solvers' intrinsic motivations, i.e. motivations associated with the fulfilment of the challenge itself (Ye and Kankanhally, 2017; Zhao and Zhu, 2014). Deciding to acquire the IPR to the winning solution, the seeker denies to that solver the possibility of using the solution she/he has generated to signal her/his competencies (Hagedorn and Zobel, 2015; Kim and Mahoney, 2002; 2005). For the winning solver, this prohibition represents a loss of potential social earnings, such as approval, status and respect; for example, the solver, through the ownership of the IPR related to that solution, could be socially recognized as an innovation partner of the seeker firm (Majchrzak and Malhotra, 2013). Thus, an IPR arrangement with a high degree of ownership, by limiting the solvers' possibilities of building or enhancing her/his reputation, reduces the probability of the solver's self-selection (Ye and Kankanhally, 2017; Zhao and Zhu, 2014).

On the basis of our discussion, the following is hypothesized:

Hypothesis 3: IPR arrangements with a high degree of ownership decrease the performance of the contest. 


\section{The mediation role of IPR arrangement}

Previous crowdsourcing scholars empirically demonstrate that the characteristics of the technical problem, such as the number of knowledge domains and the stage of development of the technical problem broadcast, by influencing the solvers' self-selection process, affect the performance of the contests (Boudreau, Lacetera and Lakhani, 2011; Franke, Keinz and Klausberger, 2013; Jeppesen and Lakhani, 2010; Terwiesch and $\mathrm{Xu}, 2008$ ). Specifically, the effect of problem attributes on contest performance is due to several reasons, such as how these attributes influence the solvers' intrinsic and extrinsic motivations (Franke, Keinz and Klausberger, 2013; Ye and Kankhanally, 2017; Zheng, Li and Hou. 2011). This means that, although it could be expected the attributes of the technical problem to affect the overall performance of the contest, there are questions related to how this effect occurs and what intervenes between the antecedents and the consequences.

In light of the argumentations underlying previous hypotheses, we argue that the IPR arrangement may act as the mediator of the relationship between the attributes of the technical problem and contest performance. As theorized in hypotheses $\mathrm{H} 1$ and $\mathrm{H} 2$ of the study, the seekers' decision about the IPR arrangement could depend on the attributes of the technical problem. The FirmB interview supported this argument: 'when you look at this piece of technology you'll understand that there's a particular issue and you say "we know we have this particular problem; we know that we want to obtain this particular piece of technology; but we're not sure quite what it is". And in that case, what you would start to look at is your relationship for the intellectual property [which] becomes interesting because you might say "well, we don't necessarily need to own the intellectual property for that particular piece of technology but we might want to acquire it or we might want to have sole use of that within our own market; or we might be interested in licensing that particular piece of intellectual property so that we can obtain a market share or bring a product to market or partner with a particular company"'. In fact, 
since the problem attributes are the only available information the seeker has when designing the challenge, they serve the seekers in assessing the value she/he can gain from owning the winning solution (Nickerson and Zenger, 2004), thereby affecting the decision whether to fully acquire or to license-in the IPR to the winning solution. As such, it could be an underestimation to suggest that a seeker simply broadcasts technical problems characterized by specific attributes and expects these attributes to deliver superior or inferior performance of the contest. Rather, the attributes of the technical problem shape the IPR arrangement, and it is the IPR arrangement that in turn, by affecting the solvers' extrinsic and intrinsic motivations, shapes the performance of the contest (as hypothesized in H3). That is, the IPR arrangement is the means through which the attributes of the technical problem increase the overall performance of the contest. Therefore, when considering the impact of the attributes of the technical problem on the performance of the contest, it should be considered that such attributes could lead to superior performance both directly and by shaping the seeker's decision about the IPR arrangement.

Thus, reflecting the arguments above the following is hypothesized:

Hypothesis 4: IPR arrangements mediate the relationship between the attributes of the technical problem (number of knowledge domains and stage of development) and the performance of the contest.

\section{DATA AND MEASURES}

\section{Research setting and data collection}

An ad-hoc database considering all of the crowdsourcing for innovation challenges hosted and awarded on the InnoCentive platform in a seven-year time frame (2010-2016) was built. InnoCentive is an emblematic example of a crowdsourcing for innovation platform, created in 2001 as a spinoff from Eli Lilly, it has hosted over 2000 challenges to date (InnoCentive, 2017; Shenk et al., 2017;). InnoCentive offers additional services to seekers that go beyond the matching of seekers with solvers, such as consulting services, assistance in the formalization of technical problems, and the management of IPR 
issues (Shenk et al., 2017). Specifically, 'InnoCentive acknowledges that management of intellectual property is of paramount importance to its business model' (de Beer et al., 2017: 216). Thus, to better investigate the role of IPR in crowdsourcing for innovation contests an empirical analysis on this platform was performed. The sample consists of 729 challenges. Secondary data for this study are collected from the RFP documents and the contest is the unit of analysis. Each observation is fixed at the awarding date and does not require a study across time; the dataset is then structured as crosssectional.

\section{Measures}

The dependent variable, Contest performance, is measured as the number of active solvers that selfselect and submit at least one solution proposal to the contest (Boudreau, Lacetera and Lakhani, 2011; Jeppesen and Lakhani, 2010; Terwiesch and $\mathrm{Xu}$, 2008). Indeed, as previously suggested, the greater the number of solvers who participate by offering a solution, the higher the performance of the contest (Zheng, Li and Hou. 2011). Such a measure is also used by most of the seekers to understand the success of a challenge, as reflected in our interview with the FirmB manager, saying that 'We've got rough metrics for overall which averages out over different challenges. When we put in a challenge, what we record is the amount of solvers that get back to us, the percentage of those solutions that are viable and of interest to us and however many we actually take forward to development stage'.

Concerning the mediator, the variable IPR arrangement measures the degree of ownership as declared in the RFP document (de Beer et al., 2017). InnoCentive's terms and conditions allow seekers to choose between two different degrees of ownership of the IPR arrangement for their challenges: high ownership in order to acquire the IPR to the winning solution and low ownership in order to license-in the IPR to the winning solution. Thus, IPR arrangement is operationalized as a binary variable assuming 
the value 1 if the seeker chooses an IPR arrangement with a high degree of ownership (acquiring IPR), 0 otherwise (licensing-in IPR).

Focusing on the explanatory variables, the Knowledge domains of the technical problem measures the different technical and knowledge areas related to the challenge as declared by the seeker in the RFP ('Business \& Entrepreneurship', 'Chemistry', 'Computer and Information Technology', 'Engineering and Design', 'Food and Agriculture', 'Life Sciences', 'Math and Statistics', 'Physical Sciences', and 'Social Innovation'). Specifically, the Knowledge domains of the challenge is operationalized as a count variable that measures the number of different areas related to the challenge (Boudreau, Lacetera and Lakhani, 2011). The Stage of development of the technical problem is measured by considering the typology of the challenge broadcast. In the InnoCentive platform, seekers can broadcast challenges related to both the early-stages (i.e. ideation and theoretical challenge) and the later-stages (i.e. reduction-to-practice challenge) of the technical problem (Jeppesen and Lakhani, 2010). Thus, the Stage of development of the challenge broadcast is a binary variable that assumes the value 1 if the challenge is a later-stage challenge, 0 otherwise.

Because both the seekers' decisions between alternative IPR arrangements and the performance of a contest could be influenced by factors other than those under investigation, several control variables are also included in the analysis. Considering the variable IPR arrangement, it was controlled for the possibility of the solvers accessing funding opportunities that would provide them financial support in solving the technical problem; Funding is a binary variable that assumes the value 1 if solvers could access financial support in solving the challenge, 0 otherwise. It was also included for the possibility that two or more seeker firms decide to broadcast a challenge together; Seeker group is a binary variable that assumes the value 1 if the challenge is broadcast by a group of firms, 0 otherwise. Finally, it was also added the binary variable, Seeker identity, which assumes the value 1 if solvers know the identity of the seeker, 0 otherwise to control for if the seeker reveals her/his identity to solvers. When considering 
the variable Contest performance, it was controlled for if the seeker reveals her/his identity to solvers using the aforementioned binary variable, Seeker identity. Moreover, it was added the Team working binary variable that assumes the value 1 if solvers could work as a team to solve a challenge, 0 otherwise to control for the possibility for a group of solvers collaborating and submitting a solution proposal as a team. It was included a binary variable to control for the effect that offering additional social rewards has on the performance of the contest (e.g. future collaboration with the seeker firm and the possibility of participating in conferences or meetings); Social reward is a binary variable that assumes the value 1 if the seeker offers a social reward beyond the prize, 0 otherwise. Evaluation method controls for whether the seeker evaluates the solution proposal internally or delegates such activity to external experts. The InnoCentive platform provides a specific service that allows seekers to entrust the assessment of the solution proposals to a judging panel of experts that helps determine the best proposals and select the winning one (Feller et al., 2012). The evaluation method is operationalized as a dichotomous variable, assuming the value 1 if the seeker refers to the external judging panel of expert evaluation, 0 otherwise. In addition, a variable was added to control for the effect of the challenge referral program on the performance of the contest. The referral program is a tool to reward a solver who plays a key role in the challenge-solving process by exposing the challenge to another solver who is able to solve it and submit the winning solution proposal (InnoCentive, 2017); Referral award is a binary variable that assumes the value 1 if the solver can receive an award referring the winner solver, 0 otherwise. Moreover, three dummy variables ('High Award', 'Low Award', 'Undeclared Award') were included to control for the effect that the Award of the challenge has on the solvers' decision to self-select for that contest (Ye and Kankanhalli, 2017). Finally, by using seven dummy variables ('Year 2010', 'Year 2011', 'Year 2012', 'Year 2013', 'Year 2014', 'Year 2015', 'Year 2016') it was controlled for the effect that broadcasting the challenge in a different Year has on the performance of the contest. 


\section{ANALYSIS AND RESULTS}

The descriptive statistics and pairwise correlation values for all the variables of the study are provided in Table 1. The pairwise correlation values reveal some criticalities for model estimations. The variable Team working is correlated with the dummy 'Year 2010'; thus, the variable Team working was not included in the models' estimation. Moreover, a strong correlation between 'Year 2012' and Referral award was found; in subsequent analyses, the dummy 'Year 2012' is used as the baseline level of the control Year so the two variables are not used in the same regression, as clearly evidenced in Table 2. Moreover, for all the models reported in Table 2, it was calculated the variance inflation factor (VIF) values, a more advanced measure of multicollinearity than simple correlations (Stevens, 1992); the VIF values of the variables are below the critical level, indicating that the explanatory variables can simultaneously be included in the models (Gujarati, 1995). Once such precautions are taken, multicollinearity is not a problem for our study.

\section{[Table 1, about here]}

Table 2 illustrates the results of the regressions performed. In order to test our hypotheses, the mediation analysis procedure proposed by Baron and Kenny (1986) was applied. Meeting the condition of this procedure, it is possible to test the mediating role of IPR arrangement in the relationship between the attributes of the technical problem (the independent variables) and the performance of the contest (the dependent variable). Specifically, a three-model system is used to analyze the mediation relationship (Muller, Judd and Yzerbyt, 2005), and following the stepwise approach (Rosenzweig, Roth and Dean, 2003), each model is first estimated using only the control variables (Model 1.1, 2.1,3.1) and then adding the variables of interest (Model 1.2, 2.2, 3.2).

\section{[Table 2, about here]}

In Table 2, Model 1.1 and Model 1.2 examine the impact of the attributes of the technical problem on the performance of the contest, without including the mediator, to find confirmation of Baron and 
Kenny's first condition. In particular, considering the nature of the dependent variable Contest performance, these two models are negative binomial regressions. Count data frequently follow a Poisson distribution and over-dispersion is a likely downside with Poisson regression, thus the Poisson assumption is tested alongside the negative binomial model via the goodness-of-fit (gof) test (Cameron and Trivedi, 1998; Hausman, Hall and Griliches, 1984). Examined in contrast to the Poisson predictions for an equivalent model $(\chi 2=205188.6, p=.000)$, the significant value for chi-square in the gof test indicates that the Poisson distribution was not appropriate. Consequently, the result support the use of the negative binomial specification for the group of models 1 (Green, 2000). Through Model 1.2, it was found confirmation for Baron and Kenny's first condition since both Knowledge domains (0.145, $\mathrm{p}<0.001)$ and Stage of development $(-0.375, \mathrm{p}<0.001)$ affect the Contest performance without controlling for IPR arrangement.

Model 2.1 and Model 2.2 test the impact of the challenge attributes Knowledge domains and Stage of development on the mediator IPR arrangement (H1 and $\mathrm{H} 2)$ assessing the second condition of Baron and Kenny's procedure. In particular, considering the dichotomous nature of the variable IPR arrangement, a probit model was used for these two models. Probit and logit models are both appropriate when the dependent variable models an alternative between two possible occurrences and convenience and convention determine the choice between them (Hoetker, 2007). Starting with the control variables, in Model 2.1, the variables Seeker group and Funding are not significant. Moreover, the variable Seeker identity is significant and has a negative coefficient, meaning that when disclosing their identities seekers choose an IPR arrangement with a low degree of ownership. The impact of the attributes of the technical problem on the IPR arrangement is represented by the coefficients of Knowledge domains and Stage of development in Model 2.1. Specifically, the coefficient for Knowledge domains is significant $(\mathrm{p}<0.001)$ and negative (-0.218). Thus, in contrast to $\mathrm{H} 1$, challenges concerning technical problems involving several technical areas reduce the likelihood of an IPR arrangement with a high degree of ownership. 
Stage of development has a significant $(\mathrm{p}<0.001)$ and positive $(1.820)$ coefficient. This means that laterstage challenges increase the probability a seeker will choose an IPR arrangement with a high level of ownership, thus supporting H2. Moreover, since the attributes of the technical problem affect the IPR arrangement, Model 2.2 confirms Baron and Kenny’s second condition.

Finally, Model 3.1 and Model 3.2 assess the impact of the attributes of the technical problem and the IPR arrangement on the Contest performance, testing $\mathrm{H} 3$ and $\mathrm{H} 4$. Following the same reasoning of Models 1.1 and 1.2, a negative binomial specification model for Models 3.1 and 3.2 (gof test: $\chi^{2}=$ 202212.1, $\mathrm{p}=.000$ ) was applied. Starting with the control variables, in Model 3.1, the dummy variables indicating the awarding year of the challenge are all significant and negative, except for 'Year 2010' and '2013', meaning that challenges awarded in 'Year 2011', 'Year 2014', 'Year 2015' and 'Year 2016' attracted a lower number of solvers than those awarded in 'Year 2012' (used as baseline). Moreover, the performance of the contest increases when seekers disclose their identities, as shown by the significant and positive coefficient of Seeker identity. Referral award is significant and has a negative coefficient, meaning that solver's participation is inhibited when seekers utilize the referral program. The dummy variable indicating a 'High award' is not significant, while 'Low award' is significant and has a negative coefficient, meaning that contest performance is lower in a contest with a low prize award than in a contest in which the award is not declared. The variables Social reward and Evaluation method are not significant. Finally, as previously discussed, the attributes of the technical problem Knowledge domains and Stage of development affect the performance of the contest, respectively, enhancing and inhibiting the participation of solvers. The effect of a different IPR arrangement on the Contest performance can be assessed by the coefficient of IPR arrangement in Model 3.2. IPR arrangement has a negative and significant coefficient $(-0.158 ; \mathrm{p}<0.05)$, suggesting that IPR arrangements with a high degree of ownership reduce the Contest performance as hypothesized in H3. Moreover, the significant effect of $I P R$ arrangement on Contest performance, when regressed together with the attributes of the technical 
problem, also confirms the third condition of Baron and Kenny's procedure. Thus, the mediating role of the IPR arrangement can be assessed.

According to Baron and Kenny (1986), once verifying the previous condition, the mediating role of IPR arrangement can be assessed by highlighting that the IPR arrangement renders the effect of the attributes of the technical problem on Contest performance. The results show that the coefficient for both Knowledge domains and Stage of development in Model 3.2 are smaller than in Model 3.1, confirming H4. However, the magnitude of the impact of the attributes of the technical problem on Contest performance has barely been reduced by the introduction of IPR arrangement. Thus, to validate the results on the mediating role of the IPR arrangement, some procedures for robustness were adopted as discussed in the following.

\section{Robustness check}

Following certain recent literature (e.g. Lin et al., 2013; Wan and Sanders, 2017), it was conducted a significance test to assess the indirect effect of the attributes of the technical problem on the performance of the contest. Such indirect effects only capture the effect of the independent variables on the dependent variable through the mediator (Fritz and MacKinnon, 2007; Hayes, 2009). The Sobel method is an easy approach to testing the significance of the indirect effect. However, the assumption of normality in Sobel's is not satisfied in this study. Hence, the bootstrapping method was employed (Bollen and Stine, 1990; Fritz and MacKinnon, 2007; Hayes, 2009). The test shows that the 95\% confidence interval of the indirect effect for both the Knowledge domains $(1.046 ; 1.161)$ and the Stage of development $(0.389$; 0.943) does not include zero, suggesting that the indirect effect of both the attributes of the technical problem are significant. Thus, the IPR arrangement mediates the relationship between the attributes of the technical problem and the Contest performance, offering more strengthened support for H4. 
Moreover, when examining simultaneous effects, a path structural modelling approach could be useful beyond the regression options for testing (Iacobucci, 2009). Thus, as performed by Chen, Bharadwaj and Goh (2017), to evaluate the robustness of the results a Structural Equation Modelling (SEM) analysis, an approach that allows to simultaneously examine all the hypothesized relationships among the focal constructs, was also conducted. The standardized path coefficients and their statistical significances for the main relationships are provided in Table 3. Before proceeding to assess the SEM results, it is good form to verify that the model fits reasonably well (Iacobucci, 2009). For our data, the model fits nicely according to the recommendations provided by the literature (Byrne and Stewart, 2006; Hair et al., 1998). Table 3 shows that the results based on the path analysis are the same as that obtained with Baron and Kenny's (1986) procedure, supporting the stability of our hypotheses testing.

\section{[Table 3, about here]}

\section{DISCUSSION AND CONCLUSIONS}

This work was motivated by important research gaps in our understanding of the IPR arrangements in crowdsourcing for innovation contests. The article investigated the influence of attributes of technical problems on the decision about the level of ownership of the IPR arrangement (high versus low ownership) when the innovation contest is broadcast. Furthermore, the consequences that this choice has on the performance of a contest was evaluated. The hypotheses that leveraged on the observations and interviews with the three cases were framed by adopting a problem solving perspective as well as the previous literature on PRT and crowdsourcing motivation. Then, the theoretical framework was assessed with data from a sample of 729 challenges broadcast on the InnoCentive platform. Thus, in this work the IPR arrangements were studied by using an ex-post data point of view, rather than ex-ante; we use interviews with managers from three companies that have engaged in crowdsourcing for innovation 
activities and real-world secondary data about solvers who have participated in a challenge and submitted solutions (Franke, Keinz and Klausberger, 2013; Ye and Kankanhalli, 2017). The empirical insights from organizations are one of the strengths of our research that we employ to show (but not make) abstract arguments and enrich our research. Moreover, using the ex-post data approach increases the internal validity of our results, since the data focuses on real behaviors rather than intentions (Bickman and Rog, 2008).

This work yielded the following findings. From the experiences and interviews, it was observed that IP in a crowdsourcing contest is considered as a critical aspect. All organizations concede that obtaining knowledge from outside is relatively challenging and mostly a reaction to technological changes and market developments. At the same time, interviewed organizations indicate that the IPR arrangements in crowdsourcing contests heavily depend on the attributes of the technical problems and that they may have different effects on the level of contest participation. These initial findings have been empirically investigated in the second step of analysis.

As such, our results show significant effects for all four hypotheses and confirmation for three since the sign for the first hypothesis is negative rather than positive. In contrast to what prior studies and the qualitative findings have suggested, it did not find a positive relationship between the knowledge required for a problem and seeker's preference towards a high ownership level. We try to provide an alternative explanation for this unexpected result. When the problems require a unique expertise and knowledge domain for technology and/or are tactical topics of the seeker, the successful approach for problem solving requires significant firm-specific human capital (Mayer, Somaya and Williamson, 2012). For instance, if a solver's solution is associated with a deep-rooted niche technology of its own firm, recognizing the market place and corresponding technologies would be invaluable for obtaining an IPR arrangement with low degree of ownership. Specifically, solutions related to more challenging technical problems that involve several knowledge domains suffer from high variability since it may not 
be clear what approach should be taken to the problem, how many possible approaches there are and what the return is of pursuing any possible approach (Boudreau, Lacetera and Lakhani, 2011). Thus, seekers could face this uncertainty by choosing an IPR arrangement with a low level of ownership. As such, seekers might need to confront clear drawbacks, comparative to a solver, in the advancement of required knowledge skills to specific human capital since they might not share a familiar terminology or communications that exist for the solver (Kogut and Zander 1992). This argument is reflected in FirmA's interview: 'Why not use someone's IP and pay for it or we try to develop our own IP with someone and pay for the development. Both have their advantages and both have disadvantages. Either way it's quite... it's really what works for a specific solution rather than worrying about IP in general'.

The second hypothesis argues that the stage of development of the technical problem affects the seekers' preference toward different ownership levels of IPR arrangements. There is a lack of definition in innovation activities that can be outsourced to crowds at different stages of the innovation process (Jarvenpaa and Tuunainen, 2013; Martini, Massa and Testa, 2014; Matzler et al., 2013). Most of the available research considered IPR arrangements at the ideation stage. Users also play a productive role during prototype testing and commercialization (Baldwin, Hienerth and Von Hippel, 2006; Franke and Shah, 2003). Brand communities, for example, act as a key catalyst in the commercialization and discovery process for innovation. The findings suggest that when broadcasting a technical problem related to the later stages of the innovation development process, the seeker has a strong interest in owning the IPR to the winning solution in order to gain monopolistic benefits and so hinder competitors. As such, this research underlines the importance of considering the development stage of innovation within the IP value chain (Reitzig and Wagner, 2010). The technical innovation contest clearly shows that not all ownership is handed over by the solvers in the development stage of innovation. The reason for this decision might be the $R \& D$ investments that were made as well as the $R \& D$ conducted prior to this stage of innovation. Seekers might aim to obtain ideas from outsiders to realize economies of scale 
whilst reducing the time and cost of extensive R\&D processes of their innovation (Veer, Lorenz and Blind, 2016).

The third hypothesis showed that IPR arrangements with a high level of ownership, claiming the acquisition of the IPR, reduce the performance of the contest compared to an IPR arrangement with a low level of ownership. Even though crowdsourcing offers an important option to lead innovation, matching the problem to the solution and attracting solvers to participate is challenging. The result supports the idea behind our investigation that solvers have concerns about losing beneficial proprietary knowledge by transferring the IPR to their submission to the seeker. Knowledge management scholars reported that 'loss of knowledge' is a barrier for knowledge sharing (Davenport and Prusak, 1998). In the crowdsourcing literature, solving a seeker's technical problem that requires a unique 'knowledge can be perceived as source of power' by the solver (Afuah and Tucci, 2012). As such, solvers may have feelings of powerlessness when seekers announce the acquisition of IP when the innovation is broadcast. This may result in potential solvers not taking part in the innovation contest.

The fourth hypothesis argued that the attributes of the technical problem affect the seekers' decision about the ownership level of the IPR arrangement, and it is the IPR arrangement that in turn, by affecting the solvers' extrinsic and intrinsic motivations, shapes the performance of the contest. Our result showed that problem attributes could increase the impact of the performance of the contest as a motivational force for solvers to participate in a challenge. However, the effect of problem attributes depends on the level of the IPR arrangement. For the seeker, the positive effect of anticipated participation in the contest becomes significant in challenges where diverse knowledge is required for the problem as well as the development stage of innovation, when the difficulties of technical innovation may be sufficiently mitigated by clearly stating the IP arrangements during broadcasting. In other words, there is a level of IPR arrangement above which the effect of problem attributes becomes significant in 
attracting more solvers. This result suggests to us that the IPR arrangement mediates the relationship between the attributes of the technical problem broadcast and overall performance of the contest.

\section{Theoretical Contributions}

Through the aforementioned findings, this research provides certain contributions to the literature. First, by examining the IPR arrangement decisions when the innovation contest is broadcast by the seeker to provide a solution to particular problem attributes this work contributes to the crowdsourcing literature addressing the ownership issue of the IPR. Although only de Beer et al. (2017) has focused on the legal issues a seeker faces when acquiring IPR from the crowd, previous research has declined to investigate the factors that determine whether seekers are more likely to acquire or license-in IPR from solvers. Specifically, by adopting the problem solving perspective (Nickerson and Zenger, 2004; Nickerson, Wuebker and Zenger, 2017) this research demonstrates that the seekers' choice between different IPR arrangements depends on the attributes of the technical problem broadcast, such as the stage of development of the technical problem and the nature of the knowledge required to solve it. Specifically, by using insights from interviews and leveraging on PRT (Alchian and Demsetz, 1972; Grossman and Hart, 1986; Hart and Moore, 1990), this study adds to the crowdsourcing literature by developing two central arguments that guide seekers in defining the legal part of crowdsourcing in a technical contest. Specifically, while previous researchers have mainly focused on the most effective IPR arrangements for a specific type of partner in collaborative innovation, our arguments focus on how the attributes of the technical problem dictate the degree of ownership (acquire or license-in the IPR to the winning solution) of the IPR arrangement in innovation contests. The first argument relates to the external field of knowledge capabilities (e.g. software engineering, chemistry, business) required to solve the innovation problem (Mayer, Somaya and Williamson, 2012). The second argument relates to the development stage of the technical problem, that is, when collaboration with solvers takes place 
considering the stage of the technical problem when it is broadcast (Manzini and Lazzarotti, 2016; Veer, Lorenz and Blind, 2016). As such, this research suggests the decision about the degree of ownership may rely heavily on the knowledge required to solve the technical problem and its development stage; for example, acquiring knowledge may be essential for long term, strategic complex problems at the development stage, instead of the ideation stage.

Second, this study provides empirical evidence that the IPR arrangement is a key driver of the performance of the contest. Previous crowdsourcing literature, recognizing the self-selection of the crowd as crucial to increase the performance of the contest, has deeply explored solvers' intrinsic and extrinsic motivations that increase the solvers' willingness to participate, such as the prize award and the attributes of the technical problem (e.g. Boudreau, Lacetera and Lakhani, 2011; Jeppesen and Lakhani, 2010; Terwiesch and Xu, 2008; Zheng, Li and Hou. 2011; Ye and Kankanhally, 2017). More recently, Franke, Keinz and Klausberger (2013) also highlighted that transparency about the terms and conditions regarding the ownership of the intellectual property affect the solvers' willingness to participate. However, so far, there were no studies considering how different IPR arrangements with different ownership levels influence the solvers' decision to engage in a crowdsourcing for innovation competition. Thus, this work extends the research on the performance of crowdsourcing contests (e.g. Boudreau, Lacetera and Lakhani, 2011; Franke, Keinz and Klausberger, 2013; Jeppesen and Lakhani, 2010; Terwiesch and Xu, 2008; Ye and Kankanhally, 2017; Zheng, Li and Hou. 2011) by including the IPR arrangement as a predictor of the self-selection process. Moreover, highlighting the mediating role of the IPR arrangement between the attributes of the technical problem and the performance of the contest, this study also adds to the crowdsourcing literature in that the attributes of the contest affect the performance of the contest both directly and through the IPR arrangements.

Finally, our research also contributes to the OI literature that, so far, has scarcely investigated the role of IPR in this context (Hagedoorn and Zobel, 2015). This literature shows an interesting debate 
that divides OI scholars between authors advocating the advantages of IPR protection for firms active in OI activities (e.g. Chesbrough and Chen, 2013; Pisano and Teece, 2007) and authors that stress the tension between IPR and OI (e.g. Pénin, 2011; Von Hippel and von Krogh 2003). In particular, the first group of authors suggests that in the OI context, IPR arrangements ensure that firms can capture value from their innovative activities since the protection offered by IPR facilitates the exchange of intellectual assets between parties. The second group of authors, on the contrary, stresses that no firm should be allowed to appropriate any intellectual asset by using an IPR mechanism. According to them, the protection offered by IPR mechanisms might threaten OI, limiting access to intellectual assets and transferring control to a single owner. Our results support those authors who highlight the necessity for firms to adopt IPR mechanisms, such as IPR arrangements, when engaging in OI activities (e.g. Chesbrough and Chen, 2013; Pisano and Teece, 2007), in opposition to those contributors who emphasize the need for only limited or no IPR mechanisms in this context (e.g. Pénin, 2011; Von Hippel and von Krogh 2003). We believe this work is amongst the first researches suggesting that firms active in crowdsourcing activities prefer to adopt specific acquisition mechanisms as value capture mechanisms in order to benefit from the innovation developed by the crowd. Specifically, by examining two types of IPR arrangements (high vs. low level of ownership) this article shows that there are differences with regard to the degree to which seeker firms may prefer to adopt acquisition mechanisms in crowdsourcing for innovation contests.

\section{Managerial implications}

The results of this research also present some implications for firm managers that engage in crowdsourcing for innovation activities, as well as for contest organizers of crowdsourcing platforms. Firm managers have to align their decisions about acquiring or licensing the IPR to the winning solution with the attributes of the technical problem they are attempting to solve. In particular, managers have to 
consider the stage of development of the technical problem at the moment it is broadcast and the nature of knowledge required to solve the problem. Since it is possible to capture a higher value from RTP challenges than from an Ideation or a Theoretical challenge, firm managers should acquire the IPR to the winning solution when broadcasting RTP challenges. In turn, managers should choose to license-in the IPR to the solution of a technical problem involving a greater number of different knowledge domains, since they may not be able to assess the quality of the solution proposals. Finally, it could be unproductive to choose an IPR arrangement without considering the effects that the IPR arrangement has on the performance of the contest. Specifically, seekers have to be aware that by choosing to acquire the IPR to the winning solution, solvers may be discouraged from participating in that contest. Thus, considering that IPR arrangements that call for the acquisition of the IPR to the winning solution can jeopardize the performance of the contest; seekers have to balance the allocation of value by offering higher monetary and non-monetary rewards to solvers that have to fully transfer the IPR to the solution they have generated.

Contest organizers of the crowdsourcing platform have to consider the mediating role played by the IPR arrangement in a crowdsourcing for innovation contest. When supporting firms in the delineation of the technical problem, platform managers have to suggest that their clients consider the stage of development of the technical problem and the nature of the knowledge required to solve it as critical attributes of the technical problem. In particular, they have to advise seeker firms to align their appropriation strategies with such problem attributes. Moreover, the crowdsourcing platform may have to suggest that their clients consider the effect of different IPR arrangements on the performance of the contest, and they have to be aware that the allocation of the contest's value is organized in such a way as to ensure solvers are not discouraged from participating in the challenge. In fact, hosting challenges that motivate solvers to participate and safeguard a fair distribution of value among seeker firms and 
solvers is vital for the crowdsourcing platform, since its success and reputation rely on the capacity to attract both parties and match their needs though crowdsourcing for innovation contests.

\section{Limitations and Future Research}

This study has two main limitations that could lead to future research directions. First, the work did not establish causality for the relationships examined. For example, sometimes alternative IPR arrangements chosen by seeker firms are consistent with a solver's capabilities and resources. Solvers might agree to IPR arrangements based on the potential they have to do it themselves. Some solvers may have an extensive engineering team and capability, as such they would like to keep their IPR instead of transferring it or having a collaborative IPR arrangement. Solvers might have a small team of two or three people and they might like the opportunity to sell the IPR and let a seeker firm take over their work.

Second, the seeker firms' industries and strategies, the importance of solving the technical problem and the necessity to quickly fix it may affect the seekers' reasoning about choosing from IPR arrangements with alternative ownership levels. However, since it is very difficult to gather data about seekers from real crowdsourcing platforms because of confidentiality issues (Natalicchio et al., 2017), our findings regarding the attributes of the technical problem in relation to IPR arrangements do not take into account such information. Future research may replicate our analyses by including additional control variables capturing more granular information about seeker firms.

Third, managers and seeker organizations are expected to be diverse in their ability or capability to deploy IPR arrangements and in their preferences toward managing open innovation relationships (Hagedoorn and Zobel, 2017). For example, the IPR arrangement decision may be influenced by the experience seekers have accumulated over their previous open innovation activities. Thus, future research may consider studying the determinants of such managerial or organization heterogeneity and 
the seekers' experiences in conducting open innovation activities in the association between innovation problems and formal acquisition mechanisms.

Finally, it may also be valuable to consider the seekers' preferences toward alternative IPR arrangements in the different phases of the innovation projects they are pursuing. In crowdsourcing for innovation contests, seekers may need to decompose their innovation problems into smaller tasks in order to make it easier for the crowd to resolve (Sieg et al., 2010; Afuah and Tucci, 2012). However, this study does not consider how problems broadcast in the contests are related to the whole innovation projects of the seekers. Thus, future research may overcome this limitation by collecting real longitudinal data about the innovation projects of the companies in order to consider the task they are broadcasting along with such innovation projects.

\section{REFERENCES}

Afuah, A. and C. L. Tucci. 2012. Crowdsourcing as a solution to distant search. Academy of Management Review 37(3): $355-375$.

Alchian, A. A. and H. Demsetz. 1972. Production, information costs, and economic organization. The American economic review 62(5): 777-795.

Ayerbe, C., N. Lazaric, M. Callois and L. Mitkova. 2014. The new challenges of organizing intellectual property in complex industries: a discussion based on the case of Thales. Technovation 34(4): 232-241.

Baldwin, C., C. Hienerth and E. Von Hippel. 2006. How user innovations become commercial products: A theoretical investigation and case study. Research policy 35(9): 1291-1313.

Baron, R. M. and D. A. Kenny. 1986. The moderator-mediator variable distinction in social psychological research: Conceptual, strategic, and statistical considerations. Journal of personality and social psychology 51(6): 1173.

Bauer, J., N. Franke and P. Tuertscher. 2016. Intellectual property norms in online communities: How userorganized intellectual property regulation supports innovation. Information Systems Research 27(4): 724-750. 
Belderbos, R., B. Cassiman, D. Faems, B. Leten, and B. Van Looy. 2014. Co-ownership of intellectual property: Exploring the value-appropriation and value-creation implications of co-patenting with different partners. Research Policy 43(5): 841-852.

Bickman, L. and D.J. Rog. 2008. The Sage handbook of applied social research methods. Sage publications.

Bollen, K. A. and R. Stine. 1990. Direct and indirect effects: Classical and bootstrap estimates of variability. Sociological methodology 20(1): 115-140.

Boudreau, K. J., N. Lacetera and K.R. Lakhani. 2011. Incentives and problem uncertainty in innovation contests: An empirical analysis. Management Science 57(5): 843-863.

Brem, A., P. A. Nylund and E. Hitchen. 2017. Open Innovation and Intellectual Property Rights: How do SMEs benefit from patents, industrial designs, trademarks and copyrights?. Management Decision 55(6):1285-1306.

Byrne, B. M. and S. M. Stewart. 2006. Teacher's corner: The MACS approach to testing for multigroup invariance of a second-order structure: A walk through the process. Structural Equation Modeling: A Multidisciplinary Journal 13(2), 287-321.

Cameron, A. C. and P. K. Trivedi. 1998. Regression analysis of count data. Cambridge: The Press Syndicate of the University of Cambridge.

Chen, Y.S. and K.C. Chang. 2010. The relationship between a firm's patent quality and its market value - the case of US pharmaceutical industry. Technological Forecasting and Social Change 77(1): 20-33.

Chen, Y., A. Bharadwaj and K. Y. Goh. 2017. An Empirical Analysis of Intellectual Property Rights Sharing in Software Development Outsourcing. MIS Quarterly 41(1): 131-161.

Chesbrough, H. 2003. The logic of open innovation: managing intellectual property. California Management Review 45(3): 33-58.

Chesbrough, H. W. and E. L. Chen. 2013. Recovering Abandoned Compounds Through Expanded External IP Licensing. California Management Review 55 (4): 83-101.

Davenport, T. H. and L. Prusak. 1998. Working knowledge: How organizations manage what they know. Boston: Harvard Business Press. 
de Beer, J., I. P. McCarthy, A. Soliman and E. Treen. 2017. Click here to agree: Managing intellectual property when crowdsourcing solutions. Business Horizons 60(2): 207-217.

Felin, T. and T. R. Zenger. 2014. Closed or open innovation? Problem solving and the governance choice. Research Policy 43(5): 914-925.

Feller, J., P. Finnegan, J. Hayes and P. O'Reilly. 2012. 'Orchestrating' sustainable crowdsourcing: A characterisation of solver brokerages. The Journal of Strategic Information Systems 21(3): 216-232.

Franke, N., P. Keinz and K. Klausberger. 2013. "Does This Sound Like a Fair Deal?": Antecedents and Consequences of Fairness Expectations in the Individual's Decision to Participate in Firm Innovation. Organization Science 24(5): 1495-1516.

Franke, N. and S. Shah. 2003. How communities support innovative activities: an exploration of assistance and sharing among end-users. Research policy 32(1): 157-178.

Fritz, M.S. and D. P. MacKinnon. 2007. Required sample size to detect the mediation effect. Psychological Science 18: 233-239.

Garavelli, A., A. Petruzzelli, A. Natalicchio and W. Vanhaverbeke. 2013. Benefiting From Markets For IdeasAn Investigation Across Different Typologies. International Journal of Innovation Management 17(06): 1340017/1- 1340017/37.

Greene, W. H. 2000. Econometric analysis. New Jersey: Prentice Hall.

Grossman, S. J. and O. D. Hart. 1986. The costs and benefits of ownership: A theory of vertical and lateral integration. Journal of political economy 94(4): 691-719.

Guba, E. G. and Y. S. Lincoln. 1982. Epistemological and methodological bases of naturalistic inquiry. ECTJ, 30(4): 233-252.

Gujarati, D.N., 1995. Basic Econometrics. New York: McGraw-Hill Inc.

Hair, J. F., R. E. Anderson, R. L. Tatham and W. C. Black. 1998. Multivariate data analysis. Upper Saddle River, NJ: Prentice-Hall.

Hart, O. and J. Moore. 1990. Property Rights and the Nature of the Firm. Journal of political economy 98(6): 1119-1158. 
Hausman, J., B. H. Hall, and Z. Griliches. 1984. Econometric models for count data with an application to the patents-R\&D relationship. Econometrica 52(4): 909-38.

Hayes, A. F. 2009. Beyond Baron and Kenny: Statistical mediation analysis in the new millennium. Communication monographs 76(4): 408-420.

Hoetker, G. 2007. The use of logit and probit models in strategic management research: Critical issues. Strategic Management Journal 28(4): 331-343.

Iacobucci, D. 2009. Everything you always wanted to know about SEM (structural equations modeling) but were afraid to ask. Journal of Consumer Psychology 4(19): 673-680.

James, S. D., M. J. Leiblein and S. Lu. 2013. How firms capture value from their innovations. Journal of management 39(5), 1123-1155.

Jarvenpaa, S. L. and V. K. Tuunainen. 2013. How Finnair socialized customers for service co-creation with social media. MIS Quarterly Executive, 12(3): 125-136.

Jarzabkowski, P. and J. Balogun. 2009. The practice and process of delivering integration through strategic planning. Journal of Management Studies 46(8): 1255-1288.

Jeppesen, L. B. and K. R. Lakhani. 2010. Marginality and problem-solving effectiveness in broadcast search. Organization science 21(5): 1016-1033.

Kavadias, S. and S. C. Sommer. 2009. The effects of problem structure and team diversity on brainstorming effectiveness. Management Science 55(12): 1899-1913.

Kermani, F. and P. Bonacossa. 2003. Patent issues and future trends in drug development. Journal of Commercial Biotechnology 9(4): 332-338.

Kim, J. and J. T. Mahoney. 2002. Resource-based and property rights perspectives on value creation: the case of oil field unitization. Managerial and Decision Economics, 23(4/5): 225-245.

Kim, J. and J. Mahoney. 2005. Property rights theory, transaction costs theory, and agency theory: an organizational economics approach to strategic management. Managerial and Decision economics, 26(4): 223242. 
Kogut, B. and U. Zander. 1992. Knowledge of the firm, combinative capabilities, and the replication of technology. Organization science 3(3): 383-397.

Lin, H. E., E. F. McDonough, S. J. Lin and C. Y. Y. Lin. 2013. Managing the exploitation/exploration paradox: The role of a learning capability and innovation ambidexterity. Journal of Product Innovation Management 30(2): 262-278.

Lopez-Vega, H., F. Tell and W. Vanhaverbeke. 2016. Where and how to search? Search paths in open innovation. Research Policy 45(1): 125-136.

Lüttgens, D., P. Pollok, D. Antons and F. Piller. 2014. Wisdom of the crowd and capabilities of a few: internal success factors of crowdsourcing for innovation. Journal of Business Economics 84(3): 339-374.

Majchrzak, A. and A. Malhotra. 2013. Towards an information systems perspective and research agenda on crowdsourcing for innovation. The Journal of Strategic Information Systems 22(4): 257-268.

Manzini, R., and V. Lazzarotti. 2016. Intellectual property protection mechanisms in collaborative new product development. $R \& D$ Management, 46(S2): 579-595.

March, J. G. 1991. Exploration and exploitation in organizational learning. Organization science, 2(1), 71-87.

Martini, A., S. Massa and S. Testa. 2014. Customer co-creation projects and social media: The case of Barilla of Italy. Business Horizons 57(3): 425-434.

Matzler, K., F. Bailom, S. Friedrich von den Eichen and T. Kohler. 2013. Business model innovation: coffee triumphs for Nespresso. Journal of Business Strategy 34(2): 30-37.

Mayer, K. J. and J. A. Nickerson. 2005. Antecedents and performance implications of contracting for knowledge workers: Evidence from information technology services. Organization Science 16(3): 225-242.

Mayer, K. J., D. Somaya and I. O. Williamson. 2012. Firm-specific, industry-specific, and occupational human capital and the sourcing of knowledge work. Organization Science 23(5): 1311-1329.

Mount, M. and G. Martinez. 2014. Social Media. California Management Review 56(4): 124-143.

Muller, D., C. M. Judd and V. Y. Yzerbyt. 2005. When moderation is mediated and mediation is moderated. Journal of personality and social psychology 89(6): 852. 
Nickerson, J. A., R. Wuebker and T. Zenger. 2017. Problems, theories, and governing the crowd. Strategic Organization 15(2): 275-288.

Nickerson, J. A. and T. R. Zenger. 2004. A knowledge-based theory of the firm-The problem-solving perspective. Organization science 15(6): 617-632.

Pénin, J. 2011. Open Source Innovation: Towards a Generalization of the Open Source Model Beyond Software. Revue d'Economie Industrielle 136: 65-88.

Pisano, G. P. and D. J. Teece. 2007. How to capture value from innovation: Shaping intellectual property and industry architecture. California Management Review 50(1), 278-296.

Reitz, M. and S. Wagner. 2010. The hidden costs of outsourcing: evidence from patent data. Strategic Management Journal, 31(11): 1183-1201.

Rosenzweig, E. D., A. V. Roth and J. W. Dean. 2003. The influence of an integration strategy on competitive capabilities and business performance: an exploratory study of consumer products manufacturers. Journal of operations management 21(4): 437-456.

Stevens, J. 1992. Applied Multivariate Statistics for the Social Sciences. Hillsdale, NJ: Lawrence Erlbaum Associates.

Terwiesch, C. and Y. Xu. 2008. Innovation contests, open innovation, and multiagent problem solving. Management science 54(9): 1529-1543.

Tietze, F., T. Pieper and C. Herstatt. 2015. To own or not to own: How ownership impacts user innovation-An empirical study. Technovation 38: 50-63.

Veer, T., A. Lorenz and K. Blind. 2016. How open is too open? The mitigating role of appropriation mechanisms in R\&D cooperation settings. $R \& D$ Management 46(S3), 1113-1128.

Von Hippel, E., and G. von Krogh. 2003. Open Source Software and the "Private-collective" Innovation Model: Issues for Organization Science. Organization Science 14 (2): 209-223.

Wan, X. and R. Sanders. 2017. The negative impact of product variety: Forecast bias, inventory levels, and the role of vertical integration. International Journal of Production Economics 186: 123-131.

Williamson, O. E. (1975). Markets and hierarchies. New York: The Free Press. 
Ye, H. J. and A. Kankanhalli. 2017. Solvers' participation in crowdsourcing platforms: Examining the impacts of trust, and benefit and cost factors. The Journal of Strategic Information Systems 26(2): 101-117.

Zhao, Y. and Q. Zhu. 2014. Evaluation on crowdsourcing research: Current status and future direction. Information Systems Frontiers 16(3): 417-434.

Zheng, H., D. Li and W. Hou. 2011. Task design, motivation, and participation in crowdsourcing contests. International Journal of Electronic Commerce 15(4): 57-88.

Zobel, A. K., B. Lokshin and J. Hagedoorn. 2017. Formal and informal appropriation mechanisms: the role of openness and innovativeness. Technovation, 59: 44-54.

Zogaj, Sh., B. Ulrich and J. M. Leimeister. 2014. Managing crowdsourced software testing: a case study based insight on the challenges of a crowdsourcing intermediary. Journal of Business Economics 84(3): 375-405.

\section{SITOGRAPHY}

innocentive.com

\section{TABLES AND FIGURES}

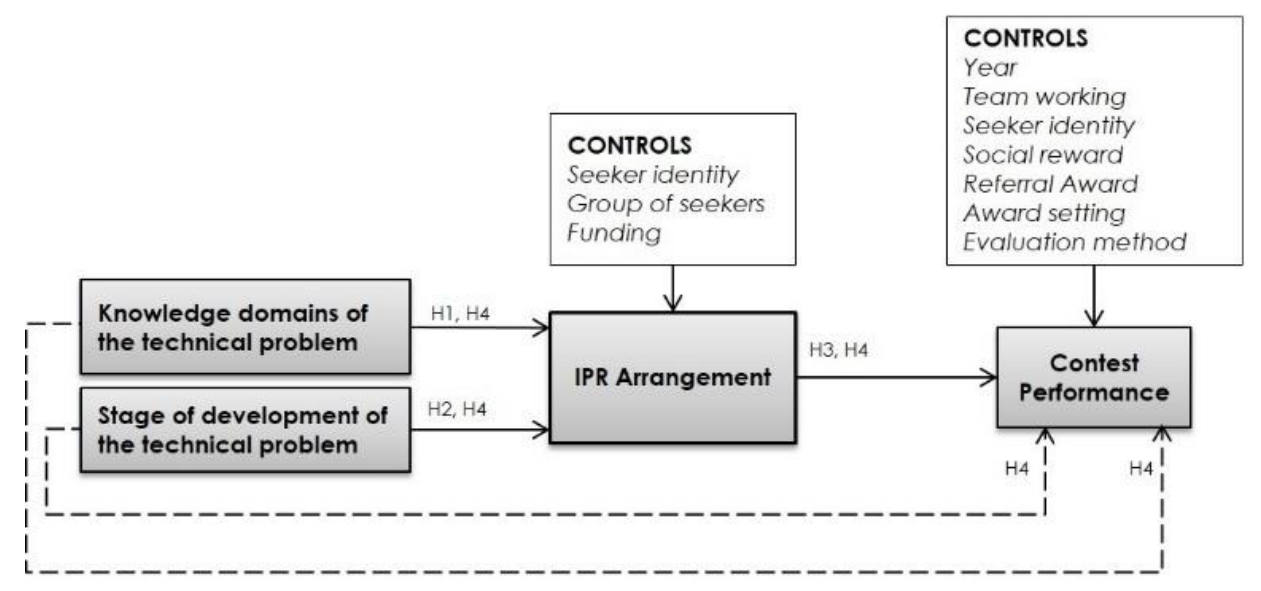

Figure 1. Research framework

\begin{tabular}{|c|c|c|c|c|c|c|c|c|c|c|c|c|}
\hline & Mean & St.Dev & VIF & $(1)$ & $(2)$ & (3) & (4) & $(5)$ & (6) & (7) & $(8)$ & (9) \\
\hline (1)Contest performance & 356.9 & 395.4 & 2.42 & 1 & & & & & & & & \\
\hline (2)IPR arrangements & 0.26 & 0.44 & 2.13 & $-0.11^{*}$ & 1 & & & & & & & \\
\hline
\end{tabular}




\begin{tabular}{|c|c|c|c|c|c|c|c|c|c|c|c|c|}
\hline (3)Knowledge domains & 2.72 & 1.27 & 1.27 & $0.16^{*}$ & $-0.33^{*}$ & 1 & & & & & & \\
\hline (4)Stage of development & 0.18 & 0.39 & 1.86 & $-0.12^{*}$ & $0.61^{*}$ & $-0.34^{*}$ & 1 & & & & & \\
\hline (5)Funding & 0.03 & 0.17 & 1.30 & 0.02 & -0.07 & 0.05 & -0.06 & 1 & & & & \\
\hline (6)Seeker group & 0.06 & 0.24 & 1.22 & $0.18^{*}$ & $-0.11^{*}$ & $0.09^{*}$ & $-0.08^{*}$ & $0.09^{*}$ & 1 & & & \\
\hline (7)Seeker identity & 0.27 & 0.45 & 1.50 & $0.21^{*}$ & $-0.22^{*}$ & $0.07^{*}$ & $-0.15^{*}$ & $0.23^{*}$ & $0.36^{*}$ & 1 & & \\
\hline (8)Team working & 0.68 & 0.47 & 2.43 & -0.03 & $-0.11^{*}$ & $0.16^{*}$ & 0.001 & $0.10^{*}$ & 0.06 & $0.11^{*}$ & 1 & \\
\hline (9)Social reward & 0.13 & 0.34 & 1.44 & $0.12^{*}$ & $-0.13^{*}$ & $0.10^{*}$ & $-0.08^{*}$ & $0.43^{*}$ & $0.21^{*}$ & $0.39^{*}$ & $0.10^{*}$ & 1 \\
\hline (10)Evaluation method & 0.02 & 0.14 & 1.09 & 0.02 & -0.06 & 0.06 & -0.07 & $0.15^{*}$ & $0.09^{*}$ & $0.18^{*}$ & 0.01 & $0.21^{*}$ \\
\hline (11)Referral award & 0.14 & 0.35 & 2.02 & -0.02 & 0.06 & $-0.09^{*}$ & $0.20^{*}$ & -0.05 & 0.04 & -0.06 & $0.22^{*}$ & -0.04 \\
\hline (12)Year 2010 & 0.17 & 0.38 & 4.40 & 0.01 & $0.19^{*}$ & $-0.25^{*}$ & -0.02 & $-0.08^{*}$ & -0.04 & $-0.13^{*}$ & $-0.61^{*}$ & $-0.11^{*}$ \\
\hline (13)Year 2011 & 0.13 & 0.34 & 3.35 & -0.01 & $0.07^{*}$ & 0.0001 & $0.14^{*}$ & -0.05 & -0.04 & $-0.11^{*}$ & $-0.33^{*}$ & -0.05 \\
\hline (14)Year 2012 & 0.13 & 0.34 & 3.76 & 0.05 & 0.02 & -0.03 & $0.08^{*}$ & -0.05 & 0.02 & -0.06 & $0.19^{*}$ & -0.01 \\
\hline (15)Year 2013 & 0.12 & 0.34 & 2.82 & 0.07 & $-0.08^{*}$ & $0.13^{*}$ & -0.05 & 0.002 & $0.15^{*}$ & -0.01 & $0.23^{*}$ & 0.001 \\
\hline (16)Year 2014 & 0.20 & 0.40 & 3.31 & $-0.09^{*}$ & -0.06 & $0.09^{*}$ & 0.01 & -0.01 & -0.01 & 0.02 & $0.29^{*}$ & 0.03 \\
\hline (17)Year 2015 & 0.14 & 0.35 & 2.65 & 0.03 & -0.04 & $0.07^{*}$ & $-0.11^{*}$ & -0.03 & $-0.07^{*}$ & 0.04 & $0.12^{*}$ & -0.05 \\
\hline (18)Year 2016 & 0.08 & 0.27 & 3.48 & -0.04 & $-0.13^{*}$ & -0.002 & -0.05 & $0.27^{*}$ & 0.004 & $0.32^{*}$ & $0.13^{*}$ & $0.24^{*}$ \\
\hline (19)Low award & 0.43 & 0.50 & 3.26 & -0.03 & $-0.48^{*}$ & $0.17^{*}$ & $-0.34^{*}$ & -0.07 & 0.04 & 0.04 & $0.10^{*}$ & -0.02 \\
\hline (20)High award & 0.16 & 0.37 & 1.79 & $0.09^{*}$ & $-0.11^{*}$ & $0.12^{*}$ & -0.07 & $0.27^{*}$ & $0.08^{*}$ & $0.27^{*}$ & $0.15^{*}$ & $0.26^{*}$ \\
\hline \multirow[t]{2}{*}{ (21)Not declared award } & 0.40 & 0.49 & 3.08 & -0.03 & $0.55^{*}$ & $-0.24^{*}$ & $0.36^{*}$ & $-0.13^{*}$ & $-0.10^{*}$ & $-0.25^{*}$ & $-0.22^{*}$ & $-0.18^{*}$ \\
\hline & $(10)$ & $(11)$ & (12) & $(13)$ & $(14)$ & $(15)$ & (16) & $(17)$ & $(18)$ & $(19)$ & $(20)$ & $(21)$ \\
\hline (10)Evaluation & 1 & & & & & & & & & & & \\
\hline (11)Referral award & 0.0001 & 1 & & & & & & & & & & \\
\hline (12)Year 2010 & -0.06 & $-0.19^{*}$ & 1 & & & & & & & & & \\
\hline (13)Year 2011 & -0.06 & -0.02 & $-0.18^{*}$ & 1 & & & & & & & & \\
\hline (14)Year 2012 & 0.004 & $0.67^{*}$ & $-0.18^{*}$ & $-0.15^{*}$ & 1 & & & & & & & \\
\hline (15)Year 2013 & -0.06 & -0.04 & $-0.18^{*}$ & $-0.15^{*}$ & $-0.15^{*}$ & 1 & & & & & & \\
\hline (16)Year 2014 & 0.05 & $-0.11^{*}$ & $-0.23^{*}$ & $-0.20^{*}$ & $-0.20^{*}$ & $-0.20^{*}$ & 1 & & & & & \\
\hline (17)Year 2015 & 0.03 & $-0.17^{*}$ & $-0.19^{*}$ & $-0.16^{*}$ & $-0.16^{*}$ & $-0.16^{*}$ & $-0.21^{*}$ & 1 & & & & \\
\hline (18)Year 2016 & $0.10^{*}$ & $-0.12^{*}$ & $-0.14^{*}$ & $-0.12^{*}$ & $-0.12^{*}$ & $-0.12^{*}$ & $-0.15^{*}$ & $-0.12^{*}$ & 1 & & & \\
\hline (19)Low award & -0.02 & 0.02 & $-0.17^{*}$ & -0.03 & $0.08^{*}$ & $0.12^{*}$ & $0.16^{*}$ & $-0.09^{*}$ & $-0.11^{*}$ & 1 & & \\
\hline (20)High award & $0.18^{*}$ & $-0.10^{*}$ & $-0.13^{*}$ & $-0.13^{*}$ & $-0.09^{*}$ & $-0.10^{*}$ & 0.01 & $0.21^{*}$ & $0.3^{\prime *}$ & $-0.39^{*}$ & 1 & \\
\hline (21)Not declared award & $-0.12^{*}$ & 0.04 & $0.27^{*}$ & $0.13^{*}$ & -0.03 & -0.04 & $-0.16^{*}$ & -0.07 & $-0.12^{*}$ & $-0.71^{*}$ & $-0.35^{*}$ & 1 \\
\hline
\end{tabular}

Table 1. Descriptive statistics and correlations 


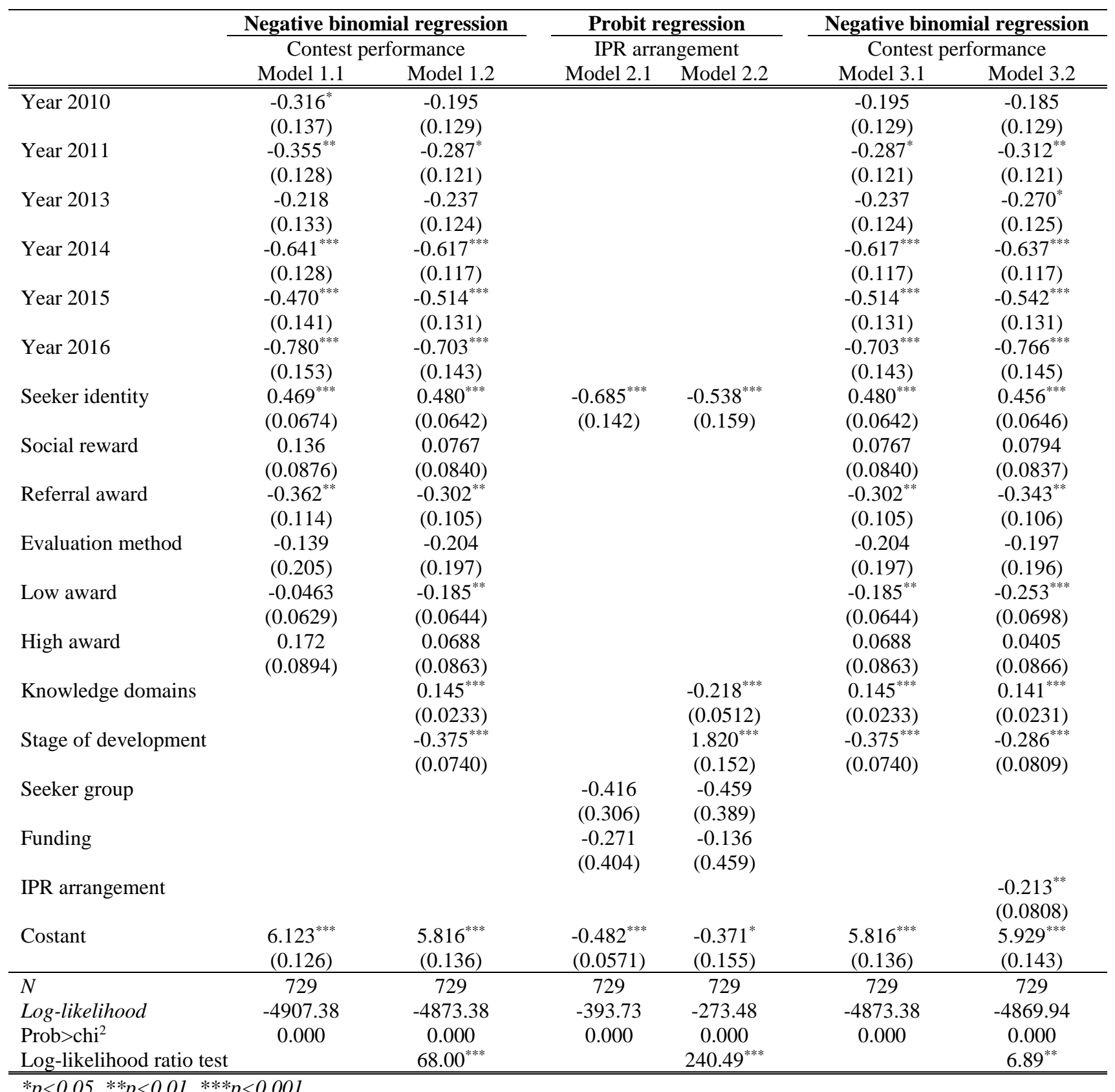

Table 2. Results

\begin{tabular}{lccc}
\hline Path & Coefficient & Std. Error & p-value \\
\hline Knowledge domains $\rightarrow$ IPR arrangement & -0.0485 & 0.0104 & 0.000 \\
RTP $\rightarrow$ IPR arrangement & 0.6127 & 0.0347 & 0.000 \\
IPR arrangement $\rightarrow$ Contest performance & -105.514 & 38.811 & 0.007 \\
\hline
\end{tabular}

Table 3. Main paths' coefficients of the structural model 


\section{ENDNOTES}

1 The programme has the aim of identifying 'innovation opportunities which are open to Scottish businesses to get involved in' (https://www.scottish-enterprise.com/knowledgehub/articles/guide/open-innovation). 